\title{
PERSPECTIVES OF OPERATIONAL ADDITIVE MANUFACTURING \\ CASE STUDIES FROM THE CZECH AEROSPACE INDUSTRY
}

\author{
Petr Jirsák \\ University of Economics, Prague, Czech Republic \\ Richard Brunet-Thornton \\ University of Economics, Prague, Czech Republic
}

\begin{abstract}
This manuscript examines the results of a quantitative and qualitative survey on Additive Manufacturing in the Czech Republic, specifically the adoption within the aerospace industry. The study conducted in 2016 and 2017 provides a general understanding of the implementation. To better gauge the experience, two intensive interviews provide a candid perspective of the challenges encountered. The discussion depicts the central issues that each enterprise encounters during this transition from traditional to Additive Manufacturing. The findings reveal that, although the transformation is on-going, a solid knowledge base remains a critical element to successful deployment.
\end{abstract}

Keywords: Additive Manufacturing, Czech Republic, Aerospace, Pilot project, 3D printing.

DOI: http://dx.doi.org/10.15549/jeecar.v6i1.273

\section{INTRODUCTION}

Additive manufacturing (AM), considered a disruptive technology of Industry 4.0 and the efforts of digital transformation, has been implemented in several industries particularly in prototyping. However, a road map to successful implementation and leverage of AM in manufacturing remains blurred. The authors use two comparative case studies to outline AM adoption in the Czech aerospace industry. Viewed as the most progressive industry for AM deployment due to the industry specifics in terms of component lightness, complexity and shape. This discussion presents the findings that encompass responses to two research questions specifically, the current state of AM adoption and the nature of a successful road map for its implementation Both aspects are analysed in the Czech Republic as a predominant and historical centre of the European aerospace industry. The existence of both international subsidiaries and local firms provides a unique environment from which to gain relevant insights within the Czech context.

The Czech aerospace industry carries with it a long and rich history dating close to a century of development and manufacturing. During the First Republic and prior to the Nazi occupation, Czechoslovakia produced numbers and retained a workforce equal to that of the military powers 
of the day, France, Germany, and Great Britain (Taxova, 2014). In addition, during the previous regime, $R \& D$ investments flourished under state-sponsored socialism. There are over 70 companies in the Czech aerospace industry today that form part of the global supply chain. Some sites are greenfield whereas others, of brownfield origin.

Additive Manufacturing (AM) is explained as the "production of parts by building up successive layers of formless material" (Kohlhuber et al., 2017). Although a rather simplistic definition, it does convey the essence of three-dimensional printing. Technologies associated with AM contrast considerably from their existing counterparts and range in market value from 500 to over $€ 1$ million. Frost and Sullivan (2016) suggests that by 2025, the aerospace along with automotive and medical industries will represent $51 \%$ of the AM market.

Christopher (2016) provides the typical factors and obstacles commonplace and often inherent within the traditional manufacturing approach. A brief summary includes rapid product completion and a high demand for service customisation. These coupled with short delivery times and the need for competitive pricing augment the complexities of the contemporary environment. Contradictory targets are often impossible to achieve in a traditional operational setting that deploys outmoded efficiency-enhancing techniques that frequently include lean Sigma Six models. As a result, management practitioners seek alternatives to completely re-engineer supply chains and operations to become sufficiently agile and efficient to deliver customised products that meet customer requirements. One possible solution to accommodate market fluctuations and changes, as well as to eliminate possible on-going service problems, is to deploy Additive Manufacturing. In doing so, this action replaces subtractive, formative, and assembling operational functions. In concert with forecasts provided by $\mathrm{Wu}$ et al. (2017), AM financial worth for 2016 represented USD 6 billion with the potential growth to USD 20 billion forecasted for 2022.

Although originated in the late 1980s (Bourell et al., 2009), the AM concept has only recently been discovered by scholars (Jin et al., 2017).
Wu et al. (2017) suggest that the AM potential resides with research and a practical association between academia and manufacturing. Although associated with Research and Development processes, implementation with production procedures remains an issue. Huang et al. (2012) suggest that AM itself is indifferent to costs where product complexity, production optimisation, and design are concerned. Subsequently, this study provides a practical insight to the latter.

\section{LITERATURE REVIEW}

Although there is not a shortage of literature relative to digital transformation, Industry 4.0 and its associated components that includes AM, the authors intentionally reviewed discussions that would benefit their study and subsequent interviews.

Additive Manufacturing is a progressive technology that attracts great research interest from both scholars and business professionals. The major areas of research are primarily concerned with the critical points of an AM road map and guidelines development in conjunction with new technological advances (Jiang et al., 2017). Hawaldar and Zhang (2018) compared the leverage of conventional sand casts to the ones produced by binder jetting technology. Two comparative case studies confirm the advantages of AM over the traditional approach in cost, lead time, and material savings. In addition, the new process rendered a better surface than injection moulding. The authors further corroborate that the AM process outperformed the previous methods in the cost advantage associated with the number of outputs. Ching-Chiang and Yi-Fan (2018) emphasise the organisational aspects for AM implementation and define the fundamental internal and external structural requirements for the seamless integration of IT and AM. Their approach is expansive as it incorporates the company as well as its external partners, technological infrastructure, and the coordination across corporate silos. Therefore, AM readiness not only involves the corporation but its entire commercial ecosystem. The authors conclude that government support is inevitable. On a further note of IT and AM, Swarup et al. (2018) propose that additive manufacturing and 
IT skills be introduced into the educational process and recommend a framework for this distinct purpose.

Thomas-Seale et al. (2018) using case study research, identified a vast number of what they consider as the major obstacles for AM execution. These include education, cost, design, software, materials, traceability, machine constraints, in-process monitoring, mechanical properties, repeatability, scalability, validation, standards, quality, inspection, tolerances, finishing and sterilisation. Benson, Triulzi and Magee (2018) analysed the applicability of Moore's Law, valid for electronic devices, if present in AM. They investigated the relevant patents for stereolithography and then extrapolated their findings to other analyses conducted on various technologies. They concluded that indeed Moore's Law is prevalent in AM and consequently, the relevant speed of technological improvements influences the AM sector. One of the critical disadvantages of current AM technology often cited by users is the apparent rough surfaces of the finished product. Lalehpour and colleagues (2018) scrutinised the pour surface of printed parts by fused deposition modelling (FDM). As a result of their study, the team proposed facilitated setups to increase surface smoothness. Indicative of the growing awareness of AM processes and technologies, efforts to employ AM in diversified sectors are common. Murmura and Bravi (2017) examined the scope of adoption within the Italian lumber industry. Likewise, Goh et al. (2018) investigated the FDM and Polyjet printing and proposed an approach to print products with embedded electro-electrical components.

\section{METHODOLOGY}

Using both quantitative and qualitative research methods recommended by Bryman and Bell (2011), the authors substantiate their findings.

AM adoption is identified as follows within specific sectors of the Czech economy associated with the distribution among studied industries.

In collaboration with Ernst \& Young Czech Republic (EY-ČR), the survey takes place during November December 2016. A self-administered web-based questionnaire serves as the canvas tool and is distributed to a potential 715 contributors. Seventy-one completed responses represent a response rate of $10 \%$. The authors select two enterprises associated with the aerospace industry, specifically aircraft, to participate in semi-structured interviews. Following which, two case studies are developed, based on the Yin (1994) observation that 2 comparative case studies suffice to produce relevant outcomes, to determine any significant aspects, real or perceived, of the complexities of AM deployment.

Table 1. AM adoption

\begin{tabular}{|l|c|}
\hline \multicolumn{1}{|c|}{ Economic Sector } & $\begin{array}{c}\text { Distribution } \\
(\%)\end{array}$ \\
\hline Aircraft and automotive & 23 \\
\hline Electronics & 6,0 \\
\hline Pharmaceuticals & 10,0 \\
\hline Chemical manufacturing & 4,0 \\
\hline FMCG & 6,0 \\
\hline Plastics & 3,0 \\
\hline Heavy machinery & 39,0 \\
\hline Others & 9,0 \\
\hline
\end{tabular}

Source: Authors

Furthermore, workforce dimensions provide an additional perspective of the above.

Table 2. Companies and Workforce Size

\begin{tabular}{|l|c|}
\hline \multicolumn{1}{|c|}{ Employees } & Companies [Number] \\
\hline $1-49$ & 8 \\
\hline $50-249$ & 23 \\
\hline $250-999$ & 30 \\
\hline $1000-5000$ & 9 \\
\hline
\end{tabular}

Source: Authors

These case studies serve to identify a roadmap useful for Czech AM introduction. Two companies are consulted, one medium-sized of Czech origin, whereas the second, a subsidiary of a large international interest. From these, the 
authors review two industry adherents that are the most AM mature. In each corporate entity, the lead technical or engineering manager responsible for AM is selected and interviewed. The names of the collaborators are coded to retain anonymity. The code EM signifies a technical manager; GK identifies an AM project manager.

To prepare sufficiently for the interview both receive the questions prior. Equally, this initiative facilitated the internal approval mechanism with their respective relevant corporate authority.

The questions comprise three components:

- preliminary investigations and subsequent steps to discover the conditions that led to AM adoption;

- dependent on the degree of AM maturity, the internal state and situation--contemporary conditions and environment, and

- once AM maturity achieved, future plans relative to orientation and strategy.

As a result of the above, the authors have developed a series of guidelines and recommendations outlining the critical path to AM introduction. The format comprises traditionally standard components of research that incorporate proof of concept, pilot project, and product or the 'sixth generation (innovation milieu mode)' as proposed by Kotsemir and Meissner (2013). Given that AM implementation is a work in progress, neither completed nor standardised, the envisioned guidelines exclude the product element.

Although AM maturity levels in some organisations remains high in areas such as $R \& D$, production, and parts inventories, global innovation is not present. Although many assume that the AM maturity level has reached its peak throughout all commercial sectors, others claim it remains largely in a development stage yet to be explored and exploited (Babu et al., 2015).

\section{Preface to Findings}

An essential premise of the research phase is that AM augments opportunities for business or enhances business models. Establishing a team of dedicated resources, essential to any project, remains a fundamental aspect of the first phase. Following which, project scope documents testing of an appropriate technology. The latter incorporates any corporate specific technologies, processes, and products. During the pilot, examination of an identified process with a specific customer becomes a central task. Lastly, the research team examines and validates the viability regarding the fundamental commercial aspects of operation, technology, cost, customer as well as any legal issues. Komi (2014) identifies the multiple reasons to adopt AM as being, "lower component weight; reduce time to market, parts customisation, design freedom, and parts consolidation" to name a few.

Hence, two research questions are formulated pertinent to the Czech Republic:

RQ 1: what is the contemporary state of AM?

RQ2: what are the guidelines or roadmaps to successful AM implementation?

The quantitative research resolves RQ1 as it maps the scope of AM adoption across various industrial sectors. In addition, findings derived from the latter, defined the suitable corporate characteristics of the qualitative research to satisfy RQ2.

\section{FINDINGS}

What is the current state of Additive Manufacturing in the Czech Republic?

Survey results identified that companies resident in the Czech Republic are aware and possess knowledge of AM (39\%). In the case of actual deployment, AM is used primarily for rapid prototyping (73\%). This selection is heavily influenced by the use of basic technologies, lower financial investments, and fewer processes when compared with production processes. 


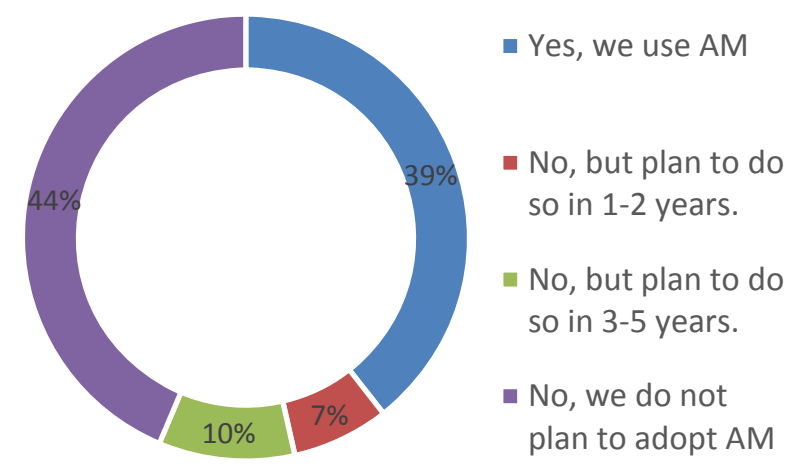

Figure 1. Adoption of AM in the Czech Republic Source: Authors

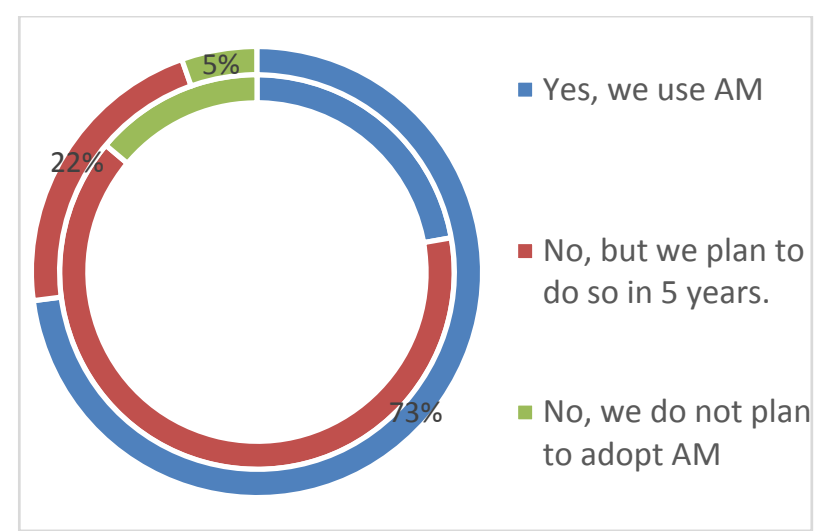

Figure 2. Adoption in production process and R\&D

Source: Authors

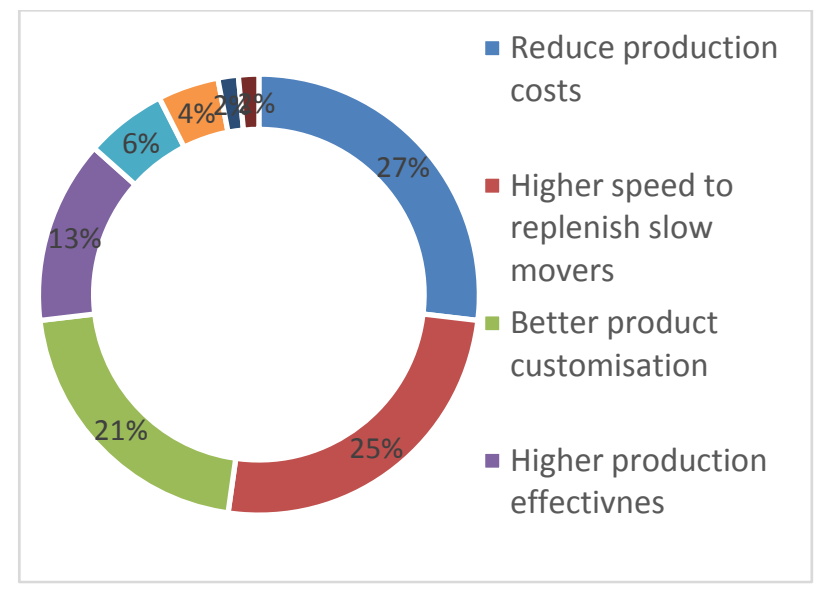

Figure 3. Benefits gained from $A D$

Source: Authors

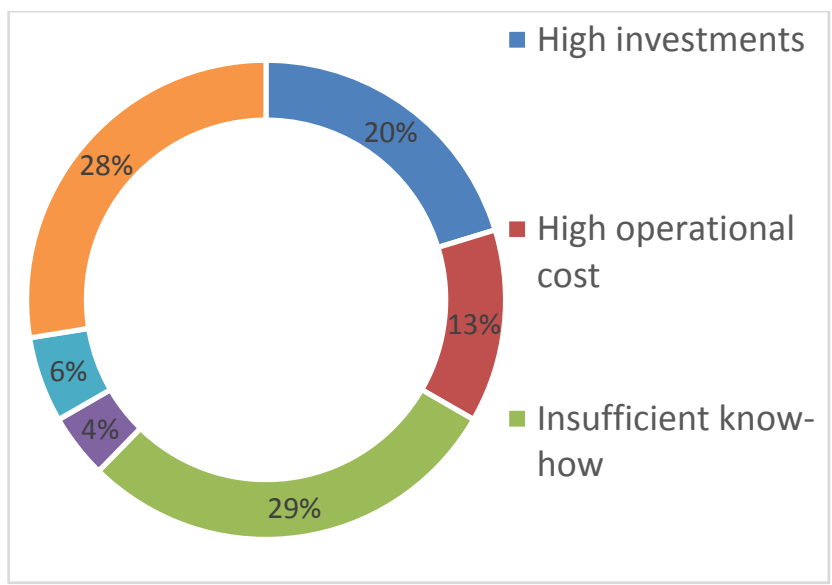

Figure 4. Perceived barriers of AM adoption Source: Authors

\section{RESEARCH}

Company A is located in the Czech Republic and of Czech origin and therefore, lacks incentives and funding from the parent company or other foreign subsidiaries to investigate AM. The initial interest largely originated from the technology manager. In 2007, he recognised the opportunities associated with AM and enhanced technologies. Due to this interest, discussions with local management were initiated that were complex and lengthy.

There was an internal discussion of a broader nature that required almost 4 years prior to taking the decision to take the first step. I appreciate the support received from my supervisor although there was little expressed interest from the company owners. Also, I might add, there was an invaluable contribution made by a long-term technology supplier. They provided us with an updated proposal on AM market availability. They went further by lending us a device and facilities to test printing at the initial stage of the project. Unfortunately, our supplier was unable to provide us reasonable case studies of similar businesses as none was available. EM

From their preliminary internal review, Company A determined that their motivation to implement AM stemmed from:

- strong belief that current technology used disrupts the business; 
- proactive attitude to new platforms and associated technologies and their possible positive impact on the business;

We are not an $R \& D$ lab but follow closely upcoming technologies from both an operational and cost sense. We're anxious to push further. EM

- estimate that AM represents an attractive advantage for the client base;

- internal labour is both motivated and skilled;

- recognised need expressed by existing and potential customers feedback;

- additional revenue generated from current client base will compensate operational costs.

Encouraged by events, the tech manager collected the necessary data and information, visited operational sites, and continued negotiations with suppliers.

Company B, unlike company A, is an international enterprise and possesses subsidiaries on a global basis. Additive Manufacturing represents a pillar of their digital strategy.

I received a call from Russia to form an internal team with members from Turkey, Portugal, France, and other countries to build an AM knowledgebase. Here, we started from scratch but there was evident motivation to do so. The beginning here in the Czech Republic was a consequence of a successful certification of a plane engine in 2015. This generated a high level of interest in AM on a global scale. GK

GK gained his AM expertise by working in Russia that in turn, was used to develop interests and know-how in the Czech subsidiary.

We were lucky that the company holds a high degree of knowledge on AM both at a local and international level. This is a great advantage to support our local national team. We can start with this and grow. Even better, we receive case studies from abroad regularly, which help to motivate my colleagues. GK

\section{PROOF OF CONCEPT}

Although Company A did not evaluate the Return on Investment (ROI), it had identified and assessed the major opportunities for the engineering process. Furthermore, there exists a strong belief that plastic production would benefit considerably. Preliminary analysis demonstrated that AM decreased the operation significantly. Despite this, a problem with quantifying the overall impact exists.

When AM shortens only the engineering leadtime, but it is not extended to other subsequent processes including logistics, then benefits are limited. We're still challenged by some of the more cynical employees that claim operations are more expensive than with the traditional approach. While this may be valid, we benefit from shorter engineering lead-times. This frees the engineer to undertake more tasks than usual. From this, we provide a higher commodity to our customers. EM

Company A decided to purchase and test the Fused Disposition Modelling technology (FDM) based largely on the positive experiences and gained expertise during the initial phase.

We purchased a small FTM device needed for the post-processing. This is really how and when we started with AM. At that time, I was the only responsible, but I succeeded in convincing a programmer to join me. Later, I extended the team by three members. We didn't hire external consultants, but our supplier was extremely cooperative. Eventually, we developed to a reasonable degree, a higher level of AM knowledge than our supplier. AM is not an easy technology, 3D models are designed, developed, and then sent to the printer. We had to work out ourselves many of the issues--problem-solving was always a hands-on experiment. This motivated us to push further. Our engineering team is very keen in this regard. Our R\&D group tested production processes on a product basis when a possibility to do so arose. This trial and error approach was significant to internal knowledge built. EM

Finally, the outcome of the Proof of Concept, as suggested by Stucker (2015) summarised:

\section{Understanding the AM process lead-time} structure

The prep phase takes anywhere from 15 minutes to an hour but depends on customer input and product complexity. Our planners add 
a buffer to the operation lead-time to be on the safe side. This gives us a space for urgent customer orders. What surprised us is the length of the post-process finalisation. Limitations existed on the size of the SDM envelope, but we managed through fixing smaller parts together. EM

\section{Technology and Material}

Although AM platforms exhibit flexibility in their functionalities and offer the user varied abilities, their specific features must be considered throughout the various stages of product development (Kohlhuber et al., 2017). In addition, Babu et al. (2015), citing a recent financial investigation, contend that AM adoption necessitates a concentrated effort on components developed expressly for this purpose.

Initially Company A deployed FDM but then extended the technology to 'Poly-jet'.

We have two FDM devices with an envelope of $90 \times 60 \times 90$ centimetres. We use these for the primary operation of medium and large parts printing. Also, to meet demand peaks, we use a smaller device. A Poly-jet device was bought but has not yet met our expectations. It can produce multicolour products but there is little demand. It has other advantages as well. Poly-jet can print varied material objects with finer textures. It is also faster than FDM but again, there is still little demand at the moment for these features. Customers tend to prefer the traditional methods that necessitate manual processing. EM

Company A uses a variety of materials based on their respective attributes.

With the AM technology, we use ABS M3O as it provides the necessary hardness for jigs and polycarbonates for the solidity. ULTEM 9085 is common as it is certified specifically for its uses within the aerospace industry. We tested numerous materials in this fashion given the numerous certifications required by the industry. EM

In addition, Company $\mathrm{A}$ tested materials against temperatures, an important attribute within the aerospace industry.

Materials should preserve characteristics up to $-50^{\circ} \mathrm{C}$. Polycarbonates and ULTEM 9085 meet this requirement but the ABS M30 devices are only to $30^{\circ} \mathrm{C}$. We also tested others on a singular or combined basis. On top of that, nylon is used to smooth surfaces. EM

The company replicates the post-processing method as each material possesses different features and characteristics. No matter the method, the product and supporting structure are separated either by water or chemical-based liquids through manual or automated extraction.

Customers are usually unaware of the type of method they need. They do have a general idea about product characteristics, but it is our decision, based on our product knowledge, to select the appropriate for the customer. Definitely, I must say that our competitive advantage stems from our AM experience and knowledge plus our individual approach to each customer. We realised early on that the customer's lack of expertise remains the principal reason why they prefer to outsource this task to us. It would take them ages at an exorbitant cost to reach our level of knowledge. EM

One essential component of an AM operation that remains critical is the support and maintenance. Although reliable technology suppliers provide on-call support, an experienced in-house, on-site surveillance is necessary. Technicians conduct continuous monitoring and troubleshooting that guarantees an effective operation with minimal outages. Effective AM cannot operate without a rigid adherence to internal standard operating procedures. Besides maintenance, production scheduling remains an essential component. Recognising the variety of materials, each requires a different temperature for printing. The transition from one material to another requires a stable programme to avoid unnecessary stoppage. Comparable to other production processes, supply material organisation is highly relevant. Company A has selected well-known and reputable suppliers thus avoiding any shortcomings in the supply chain.

The delivery time is sufficiently short from 3 days to one week. Seldom are there issues with stock as the demand coverage is five days. Different customer segments may require a day 
whereas, others up to 2 weeks. In this case, we forecast some volumes while others are based on actual customer orders. The production schedule is not rigidly followed similar to other production technologies on-site. This of course, creates peaks and valleys that impact our stock turnover. In some cases, it may hasten stock consumption. EM

The proof of concept provides a clear definition of technology, material, as well as the applicability to specific projects and customer segments. From their experience, the company cites $\mathrm{AM}$ as a competitive and innovative advantage.

Company B produces aircraft engines with their main concern relative to metals used as inner engine components.

At the beginning of our review my main concern was with the internal engine components. My thoughts at the time were centred on $A M$ deployment, component by component. GK

The criteria used comprise part size, composition, complexity, and certification.

Composition was important. 40 centimetres was good to fully utilise the envelope. Then I moved on to other elements that contain multiple metal parts as AM would no longer need the 'screwing, welding, or soldering' manipulations. I did reject those compositions that needed the existing mould. The cost would have evaporated our potential savings brought on by AM. I then selected parts that do not require certification or are of a non-critical nature. $G K$.

Company B decides to test AM on material composition and parts engineered for their traditional production. To do so, they must develop a digital model. This in turn, inevitably complicates the process. Although AM provides a possibility to create various component shapes, the shape of those traditionally manufactured components requires adjustments for the production process. To resolve this issue, Company $\mathrm{B}$ incorporated decision-making within the AM design engineering. This contributes to the effectiveness of the overall production and adds to the operational effectiveness due to lower fuel consumption and other concessions.
We may not be an R\&D lab, but we only employ technologies that better the less than five-year ROI. GK

One significant limitation within the AM operation is print speed that is constantly improved with the purchase of newer and faster devices.

We are mainly concerned with the larger size components. We have already documented results from our analysis of the smaller parts. Traditional production took 76 days and 52 activities to accomplish the end result. AM has reduced this to 10 activities within 14 days for the same results. GK

The time reduction has an enormous impact on the supply chain.

AM deployment reduce production and logistics by between 20 and 25\% in the small compositions. For the larger compositions of $200+$ parts up to $60 \%$. GK

There are other benefits such as the overall lower operational costs associated with the final product. Yet another critical aspect of AM is the post-processing operations that represent labour, time, and ultimately cost.

Our selection of components comprises those subject to an easy post-processing. What surprised us though was the customers' attitudes towards product surfaces. People still prefer the smooth appearance of the component but do not realise that this too was a consequence of the old 'screwing, pressing, and welding' sequence. Of course, this is still possible with AM, at a higher cost. What boggles the mind is that once assembled, it is out of sight. Does this make sense? GK

The case of aesthetics versus effectiveness may require Company $\mathrm{B}$ to compromise or to educate their client base that the 'new look' does not hinder the functionality. This problem has been addressed by Jiang et al. (2018) wherein several solutions are proposed to resolve problems of this nature.

\section{Pilot Project}

Company A considers the purchase of a jet fusion device to extend product scope. This device increases capacity and speed to fifteen times higher than the current period also retains 
the same mechanical characteristics unlike FDM. In essence, this technology is more suitable for series rather than customised production.

Nonetheless, AM scope extension is only in polymers. EM

The company also ponders expansion in glass but not necessarily in the immediate future.

We foresee many new opportunities with the technology and potential business. We do, however, have to conduct further studies and prepare samples with our customers and suppliers. At the moment we are uncertain of the demand. EM

While future plans are evaluated, the company continues to investigate current opportunities to extend FDM capacity. With the purchase of a $90 \times 60 \times 90$-centimetre envelope, the company then possesses the majority share of capacity in the Czech Republic.

Extension of the post-processing washing machines would have to follow to avoid bottlenecks. AM still remains inexpensive when compared with other European countries due mainly to our labour costs. The costs of materials and devices remain the same no matter where. Some AM technologies are rather intensive when it comes to the manual postprocessing. This then makes the difference between us and our western neighbours.

Within Company B, AM projects increase thus, permitting the company to seek certification for these products. This AM expansion through multiple projects and successful deployment accelerates throughout the Czech Republic. Newer technologies are considered.

We're working to increase the share of $A M$ components in our engines. GK

The current share of these components in overall engine weight is $35 \%$ of which $10 \%$ are AM.

What can significantly help us is a higher size of the AM envelope. GK

Through an acquisition, the AM technology provider now forms part of Company B. This acquisition provides the necessary knowledge and expertise to develop the devices internally without reliance on external sources. Company
$B$ is very protective of their knowledge base and are often reticent to share, even with their suppliers.

We're launching a new AM device with a larger envelope and four lasers that impact production speed. Doing this, increases capability to use AM in series production. GK

Post-processing limitations are a major corporate concern to the extent that automated processes embedded in the AM machine are contemplated. Fulfilment of this goal is essential to AM series production. One major obstacle remains the aircraft component certification. The company remains confident in future AM prospects and incorporates AM from the start of the $R \& D$ phase. The ultimate goal is to become the initiator of standards in this field.

\section{DISCUSSION}

Both studied companies serve as business examples of the prospect to enhance manufacturing and supply chain performance while providing market opportunities for their customers. The authors propose a transformational road map that consists of research, proof of concept, pilot project and finally, a customer service package. The research phase encompassed resource gathering, know-how, assets, hardware and software, to initiate the testing segment. This would not have been possible without the active participation, dedication, and interest of their respective team managers and members.

As mentioned previously, AM is a disruptive technology for which successful adoption unavoidably requires technological, informational, organisational, and business model readiness. The quantitative survey conducted in the Czech Republic confirms that business is familiar with the technology and that use is limited to prototyping. This experience inspires the participants to develop further software, hardware, and knowledge sources to expand the manufacturing process. The reverse, however, is also significant wherein some decide not to do so. Businesses still do not leverage AM-associated opportunities to their fullest. Oftentimes, the envisioned expansion is hindered by challenges created by the high investment and operational cost although moderated by Moore's Law. The dominant 
barrier remains the lack of sophisticated 'knowhow' and maturity of the industry ecosystem. The two case studies demonstrate that the process is time intensive with an extended learning curve interspersed with episodes of 'trial and error'. Both technology providers and manufacturing users seek to improve their knowledge levels and in doing so, achieve a working degree of expertise. Based on this premise, future AM implementation becomes a simpler task, one comparable to the implementation of automated welding or robotic cutting. However, the hesitation, and delays apparent during the period of anticipated expertise and maturity, restricts the opportunity to establish a competitive advantage.

\section{CONCLUSIONS}

The case studies demonstrate the extent by which AM applications benefit the Czech aerospace industry. AM requires inexpensive supplier technologies, materials and subsequently, organisational change unlike contemporary production implementation. As the first step to maturity, this enables companies to gather both data and experience to maintain current traditional approaches or to further extend the applications, or outsource, if required. Suppliers provide initial technological insights that become incentives to the user to pursue further development. It requires an enthusiastic technical team sufficiently dedicated to the project. Management must push AM in terms of budget, training, technology, and possible applications. Without this internal effort, the company encounters obstacles created by high investments, operational costs, and knowledge barriers. The extension of AM adoption throughout the supply chain subsequently augments financial benefits. From their gained experiences and acquired know-how, both corporate entities are capable to select the proper components and products suitable for AM. These lessons learnt improve the technical and economic returns. The case studies emphasise that AM deployment, at least in the Czech Republic, represents a long-term progression that requires support and commitment from operational and strategic management. AM does have a significant role within existing production technologies but remains a complementary option rather than the prevailing approach. (Holweg, 2015; Rogers et al, 2016).

To better assess the Czech condition, further research is required to extend to other 'national' industries, in particular, the automotive, to assess the quality and quantity of similar practices. Based on this supplemental examination, the compilation of an industrybased national guideline as a research end product becomes feasible.

\section{ACKNOWLEDGEMENT}

This paper is one of the research outputs of the project IGA VŠE No. IP305027 financially supported by the University of Economics, Prague in conjunction with the Centre for Digital Transformation.

\section{REFERENCES}

Babu, S., Love, L., Dehoff, R., Peter, W., Watkins, T., \& Pannala, S. (2015) Additive manufacturing of materials: Opportunities and challenges. MRS Bulletin: Volume 40, December 2015.

Barata, J., da Cunha, P., \& Coyle, S. (2018) Guidelines for Using Pilot Projects in the Fourth Industrial Revolution. 29th Australasian Conference on Information Systems (ACIS), At Sydney, Australia Retrieved December 20, 2018 from https://www.researchgate.net/publication/3 29365498_Guidelines_for_Using_Pilot_Proje cts_in_the_Fourth_Industrial_Revolution

Benson, L., Triulzi, G., \& Magee, L. (2018) "Is There a Moore's Law for 3D Printing?" 3D Printing and Additive Manufacturing. Vol. 5., pages 53-62.

Bourell, D. L., Beaman, J. J., Leu, M. C., \& Rosen, D. W. (2009). A Brief History of Additive Manufacturing and the 2009 Roadmap for Additive Manufacturing: Looking Back and Looking Ahead. Istanbul: RapidTech.

Bryman, A., \& Bell, E. (2011). Business Research Methods. London: Oxford Textbooks.

Christopher, M. (2016). Logistics and Supply Chain Management. London: Financial Times/Pearson Education. 
Frost and Sullivan (2016). Global Additive Manufacturing Market Forecast to 2025.

Retrieved 20 December 2018 from http://namic.sg/wpcontent/uploads/2018/04/global-additivemanufacturing-market_1.pdf

Goh, G.L., Agarwala, S., Goh, G.D. et al. (2018) "Additively manufactured multi-material free-form structure with printed electronics". International Journal of Advanced Manufacturing Technologies 94: 1309.

Hawaldar, N., \& Zhang, J. (2018). “A comparative study of fabrication of sand-casting mould using additive manufacturing and conventional process". The International Journal of Advanced Manufacturing Technology, 97(4), 1037-1045.

Holweg, M. (2015). "The limits of 3D printing," Harvard Business Review Digital Article, Retrieved December 20, 2018 from https://hbr.org/2015/06/the-limits-of-3dprinting

Huang, S. H., Liu, P., Mokasdar, A. \& Hou, L. (2012). Additive manufacturing and its societal impact: a literature review. International Journal of Advanced Manufacturing, 65(5-8).

Jiang, J., Xu, X., \& Stinger, J. (2018). Support Structures for Additive Manufacturing: A Review. Journal of Manufacturing and Materials Processing 2018, 2, 64.

Jiang, R., Kleer, R., \& Piller, F., (2017). "Predicting the future of additive manufacturing: $A$ Delphi study on economic and societal implications of 3D printing for 2030," Technological Forecasting and Social Change, Elsevier, vol. 117(C), p. 97.

Jin, Y., Ji, S., Li, X., \& Yu, J. (2017). A scientometric review of hotspots and emerging trends in additive manufacturing. Journal of Manufacturing Technology Management, 28(1)

Kohlhuber, M., Kage, M. \& Karg.M. (2017) Additive Manufacturing. München: National Academy of Science and Engineering.

Komi, E. (2016) Design for Additive Manufacturing. Retrieved December 20, 2018 from https://www.vtt.fi/inf/julkaisut/muut/2016/
VTT-R-03159-16.pdf

Kotsemis, M., \& Meissner, D. (2013) Conceptualizing the Innovation Process--Trends and Outlooks. National Research University Higher School of Economics, Working Paper. Retrieved December 20, 2018 from https://mpra.ub.unimuenchen.de/46504/1/MPRA_paper_46504. pdf

Lalehpour, A., Janeteas, C. \& Barari, A. (2018) "Surface roughness of FDM parts after postprocessing with acetone vapor bath smoothing process". International Journal of Advanced Manufacturing Technology (2018) 95: 1505

Murmura,F. \& Bravi,L. (2018) “Additive manufacturing in the wood-furniture sector: Sustainability of the technology, benefits and limitations of adoption", Journal of Manufacturing Technology Management, Vol. 29 Issue: 2, pp.350-371.

Rogers, H., Baricz, N. \& Pawar, K.S. (2016), “3D printing services: classification, supply chain implications and research agenda," International Journal of Physical Distribution \& Logistics Management, Vol. 46 No. 10.

Stucker, B. (2015) Recent trends in Additive Manufacturing and the Need for Predictive Simulation. Retrieved December 20, 2018 from https://additiveworld.com/upload/file/Addit ive\%20World\%20keynote\%20_\%20Brent\%20S tucker.pdf

Swarup Sharma, Rahul, Singhal, Ishant \& Gupta, Shivam. (2018). "Innovative Training Framework for Additive Manufacturing Ecosystem to Accelerate Adoption of ThreeDimensional Printing Technologies". 3D Printing and Additive Manufacturing. 5. 10.1089/3dp.2017.0003.

Taxova, M. (2014) Aerospace Market Profile Czech Republic. Canadian Trade Commission. Retrieved December 20, 2018 from https://www.enterprisecanadanetwork.ca/_ uploads/resources/tradecommissioner.gc.ca Aerospace_Market_Profile_Czech_Republic. pdf

Thomas-Seale, L.E.J., Kirkman-Brown, J.C., 
Attallah, M.M., Espino, D.M. \& Shepherd, D.E.T. (2018) "The barriers to the progression of additive manufacture: Perspectives from UK industry," International Journal of Production Economics, Elsevier, vol. 198(C), pages 104118.

Wu, B., Myant, C., \& Weider, S. (2017) The value of additive manufacturing: future opportunities. Imperial College London, Briefing Paper No 2, September 2017

Yin, R. K. (1994). Case study research: Design and methods. London: Sage Publications

Yeh, Ching-Chiang \& Chen, Yi-Fan. (2018). "Critical success factors for adoption of 3D printing". Technological Forecasting and Social Change. 132. 10.1016/j.techfore.2018.02.003.

\section{ABOUT THE AUTHORS}

Richard Brunet-Thornton, email: richard.brunetthornton@vse.cz

Dr. Richard Brunet-Thornton, FRSA, MIM, MBA is a member of the Department of Management, Faculty of Business Administration of the University of Economics, Prague. Is Managing Director of the Cross-Cultural Management Centre and Executive Consultant of the Centre for Digital Transformation. Research interests are centred on intercultural management and communications, intercultural negotiation styles, cultural anthropology and ethnology, and cross-cultural knowledge management. Given his 45-year experience in the IS/IT industry, Richard's interest includes international project management and the cultural aspects of digital transformation. He holds editorial positions on various scholarly journals and publications. Richard is a Fellow of the Royal Society of the Arts (UK) and a member of the American Psychological Association.

Dr. Petr Jirsák is a member of the Department of Logistics, Faculty of Business Administration of the University of Economics, Prague. Managing Director of the Centre for Digital Transformation. Research interests include supply chain processes such as, demand planning, supply planning and management, warehousing and logistic services, logistic providers, global supply chain strategies, employment of lean management in supply chain processes, implementation road maps and automation and digitalization strategies, municipal logistics in the era of Smart Cities and last but not least, the impact of additive manufacturing on supply chain performances. Petr conducts research for the Technological Agency of the Czech Republic and the Ministry of Transportation. Recent involvement comprised municipal logistics and waste collection using the IoT. Equally, Petr provides consulting services for private enterprise in the areas of distribution strategies and warehousing. Petr regularly presents his findings and recommendations at both academic and professional conferences. 